\title{
Structure Optimization of Tailored lonic Liquids and Process Simulation for Shale Gas Separation
}

Liu, Xinyan; Chen, Yuqiu; Zeng, Shaojuan; Zhang, Xiangping; Zhang, Suojiang; Liang, Xiaodong; Gani, Rafiqul; Kontogeorgis, Georgios M.

Published in:

AIChE Journal

Link to article, DOI:

10.1002/aic.16794

Publication date:

2020

Document Version

Peer reviewed version

Link back to DTU Orbit

Citation $(A P A)$ :

Liu, X., Chen, Y., Zeng, S., Zhang, X., Zhang, S., Liang, X., Gani, R., \& Kontogeorgis, G. M. (2020). Structure Optimization of Tailored lonic Liquids and Process Simulation for Shale Gas Separation. AlChE Journal, 66(2), [e16794]. https://doi.org/10.1002/aic.16794

\section{General rights}

Copyright and moral rights for the publications made accessible in the public portal are retained by the authors and/or other copyright owners and it is a condition of accessing publications that users recognise and abide by the legal requirements associated with these rights.

- Users may download and print one copy of any publication from the public portal for the purpose of private study or research.

- You may not further distribute the material or use it for any profit-making activity or commercial gain

- You may freely distribute the URL identifying the publication in the public portal 
Structure Optimization of Tailored Ionic Liquids and Process Simulation for Shale Gas Separation

Xinyan Liu ${ }^{\mathrm{a}, \mathrm{b}}$, Yuqiu Chen ${ }^{\mathrm{a}}$, Shaojuan Zeng ${ }^{\mathrm{b}}$, Xiangping Zhang ${ }^{\text {b,c*, }}$, Suojiang Zhang ${ }^{\mathrm{b}}$, Xiaodong Liang ${ }^{\text {a }}$, Rafiqul Gani ${ }^{\text {d,e }}$, Georgios M. Kontogeorgis ${ }^{{ }^{a *}}$

${ }^{a}$ Department of Chemical \& Biochemical Engineering, Technical University of Denmark, DK 2800

Kgs. Lyngby, Denmark

${ }^{b}$ Beijing Key Laboratory of Ionic Liquids Clean Process, CAS Key Laboratory of Green Process and Engineering, State Key Laboratory of Multiphase Complex Systems, Institute of Process Engineering, Chinese Academy of Sciences, Beijing 100190, China

c Dalian National Laboratory for Clean Energy, Dalian 116023, China

${ }^{d}$ PSE for SPEED, Skyttemosen 6, DK-3450 Allerod, Denmark

${ }^{e}$ College of Control Science and Engineering, Zhejiang University, Hangzhou, China

*Corresponding author

Email address: gk@kt.dtu.dk;xpzhang@ipe.ac.cn

\section{Abstract}

Shale gas, as a potential substitute for energy source, requires important processing steps before utilization. The most common separation technology applied is distillation, which is energy-intensive. With good stability, non-volatility and tailored properties, ionic liquids (ILs) are regarded as novel potential solvents and alternative media for gas absorption. Therefore, a new strategy for hybrid shale gas separation processing, where IL-based absorption together with distillation is employed for energy-efficient and cost economic gas processing, is developed. In this work, a This article has been accepted for publication and undergone full peer review but has not been through the copyediting, typesetting, pagination and proofreading process which may lead to differences between this version and the Version of Record. Please cite this article as doi: 10.1002/aic.16794 
three-stage methodology for shale gas separation process is proposed: IL screening, where a systematic screening method with two options (database screening and computer-aided design based on UNIFAC model) is established; suitable ILs are selected as promising candidates; process design and simulation, where separation schemes and important design issues in the IL-based processes are determined; and, process evaluation, where the performance of the final separation process is evaluated and verified.

\section{Introduction}

Coal has been a primary energy source since the industrial revolution. With increasing environmental pollution and decreasing energy sources, finding alternative energy sources is very important. With a large potential amount available for utilization, shale gas, as a kind of natural gas trapped within shale formations, has been receiving much attention. In addition to its important role as a fuel, shale gas is also a source of hydrocarbons for petrochemical feedstocks to produce value-added chemicals. Due to the presence of large amounts of $\mathrm{CH}_{4}$ and reasonable amounts of $\mathrm{C}_{2} \mathrm{H}_{6}$, many studies have been undertaken on natural gas and shale gas related to the production of potential products such as syngas, methanol and ethylene ${ }^{1,2}$. Although it is usually regarded as a "clean" fuel compared to other fossil fuels, the shale gas found in reservoir deposits is not strictly "clean" and free from impurities. It is primarily composed of $\mathrm{CH}_{4}$, considerable amounts of light and heavier hydrocarbons as well as contaminating compounds such as $\mathrm{CO}_{2}, \mathrm{H}_{2}, \mathrm{H}_{2} \mathrm{~S}$, etc. ${ }^{3}$. Thus, the impurities must be removed before their utilization to meet strict pipe-line quality standards 
specifications for a consumer fuel to avoid pipeline and equipment corrosion as well as to enhance its calorific value. Therefore, different technologies need to be employed for the separation of unwanted gases. The most common separation technology applied is distillation, which consumes large amounts of energy to give the desired high purity products ${ }^{4}$. These distillation columns operate at low temperatures and high pressures and have high energy demands. Therefore, an alternative scheme, a hybrid shale gas separation scheme, which combines distillation with absorption to achieve the desired separation at lower energy consumption, is proposed.

With the unique properties of good stability and non-volatility, ionic liquids (ILs) are regarded as attractive mass separating agents for gas absorption ${ }^{5}$. In this work, a hybrid gas separation process synthesis to separate a model shale gas mixture is proposed with a workflow. The designed flowsheet consists of distillation and IL-based absorption for a model five-component shale gas. As large amounts of solubility of $\mathrm{CO}_{2}$ in ILs data are available ${ }^{6}$, most of the developments related to the use of ILs for gas absorption have focused on the $\mathrm{CO}_{2}$ absorption in different ILs ${ }^{7,8}$, including introducing new structures in common ILs ${ }^{9-11}$. Zhang et al. ${ }^{12,13}$ reviewed the $\mathrm{CO}_{2}$ absorption with different types of $\mathrm{IL}$, ranking them in terms of $\mathrm{CO}_{2}$ solubility for different anions with the same cation. Encouraged by good absorption of $\mathrm{CO}_{2}$ with ILs, new studies have concentrated on the solubility of other gases in ILs. Lei et al ${ }^{14}$ have summarized solubility data of different gases in ILs over a wide range of temperatures and pressures, indicating a high-potential for IL application. However, as many ILs that may be potentially applicable are identified, selection of the most 
appropriate IL for specific gas absorption for different gases also needs to consider. In addition to the solubility of the selected gas in ILs, the selectivity of the gases to be separated is also very important, together with other pure component properties of ILs, such as viscosity, melting point and density. Therefore, before a selection-screening method for ILs for use in absorption based gas separation can be developed, the needed properties must be available in the form of data or property models from which they can be reliably estimated.

Some researchers have developed different thermodynamic models for gas solubility estimation, such as the equation of state models ${ }^{15,16}$, COSMO-RS ${ }^{17}$ and UNIFAC ${ }^{18}$, while, GC-based models ${ }^{19,20}$ have been used for estimation of pure component properties. With the binary interaction parameters regressed from experimental data, the UNIFAC model has been found to give good quantitative prediction accuracy for specific gas-IL systems. Moreover, as a group contribution-based model, it is very useful for a quick and reliable solvent screening ${ }^{21}$, 22. Having the UNIFAC model available, the optimal IL for gas separation can be designed through a computer-aided molecular design approach ${ }^{23}$. Zhen et al. ${ }^{24}$ have developed a UNIFAC-IL model and found the optimal solvent for extractive desulfurization of fuel oils through computer-aided IL design.

Current studies published regarding different IL-based separation processes either emphasize on IL design ${ }^{24}$ or on process simulation with an improvement of energy-reducing and cost-saving ${ }^{5,25-31}$. However, in our study, we have followed a multi-scale research strategy which includes an extended database and models from 
the view molecular to the macroscopic engineering aspect. These models have been applied to IL-based gas separation in this work. This method includes ILs screening and design, process design and simulation, as well as process assessment. In our previous work, experimental data for the solubility of gases in different ILs were collected and a UNIFAC-IL model was developed for different gas-IL systems by regressing binary parameters with available experimental data ${ }^{32}$. To lay a solid foundation for IL screening and design, an extended database and pure component property prediction models are firstly established in this work. In addition to applying only one technology (IL-based absorption), a hybrid scheme including IL-based absorption and distillation to separate a model shale gas mixture is developed and evaluated.

\section{Methodology}

In this work, a three-stage methodology is proposed (Figure.1) in order to synthesize and design IL-based shale gas separation processes. The first stage involves IL screening where the separation problem is defined and the gas mixture is analyzed. Then appropriate IL is selected based on available and predicted solubility and selectivity for specific gas separation problems. This stage includes a systematical method of screening the appropriate solvent for a multi-component gas mixture separation. The screening method has two options: a) selects the IL-based on its availability and already known properties; b) generates and selects IL candidates through computer-aided molecular design techniques that best match the desired 
target properties. In option $b$, appropriate thermodynamic models for the prediction of properties need to be employed. The UNIFAC model is used to predict solubility of gas in ILs, while COSMO-RS model is employed as a backup model when parameters of UNIFAC model are unavailable. Also, group contribution models for prediction of pure properties prediction are needed. These models constitute a model library through which not only potentially better ILs could be designed but also existing ILs not selected in option-a could now be considered based on available data as well as estimated missing properties, thereby, extending the application range of the IL screening method. The second stage involves process design and simulation for the gas separation problem for both selected ILs. The gas separation sequence is decided for each IL and the corresponding separation schemes are generated. The required thermodynamic models for the simulation of the selected gas-IL systems are established through fitting of needed model parameters from experimental data or predicted data. After verification of the model (to make sure the simulation results are correct), the whole process is simulated. The important design parameters such as the amount of solvent needed, operating conditions (temperature and pressure), are determined through sensitivity analysis on the separation performance. The third stage involves process evaluation, where the total energy consumption and selected economic performance indicators are calculated. Then the process is verified with an acceptable design decision. The results obtained for different IL-based processes with selected ILs from the first stage are compared. As a case study, in this work, two ILs are selected as candidates, one is selected from option-a employing database search to 
identify the most appropriate IL (for immediate application as the IL already exists), while, a second IL is generated and selected through option-b, having better selectivity and other missing properties. Note that this second IL could be an existing IL that could not be selected previously because of missing properties, or, a potentially attractive candidate for possible future synthesis as it is not currently available. The comparison indicates whether the potential improvements are sufficient to invest in the development of the new IL, providing a foundation of a comprehensive objective-oriented design from molecule to the whole process.

\section{ILs Screening}

\subsection{Problem Definition and Gas Mixture Analysis}

For a given gas mixture separation problem, the absorbed gas and products are first defined. In this work, based on the reported raw shale gas ${ }^{3}$, a model with 5 gases is considered, as given in Table 1 . We assume that $2000 \mathrm{kmol} / \mathrm{h}$ of raw shale gas is available at 30 bar and $20^{\circ} \mathrm{C}^{2}$. In order to have low solvent consumption, the gas present in the largest amount (methane, $\mathrm{CH}_{4}$, whose concentration is $80 \%$ ) is not absorbed and the other gases are removed, if necessary. For example, if the processed shale gas is to be used as fuel, it is necessary to remove $\mathrm{CO}_{2}$, which is present in the raw shale gas, giving a gas mixture of $\mathrm{H}_{2}$ and $\mathrm{CH}_{4}$, which can be utilized as a high-quality fuel. Note that economically feasible separation of high purity $\mathrm{C}_{2} \mathrm{H}_{4}$ and $\mathrm{C}_{2} \mathrm{H}_{6}$, which are regarded as common building blocks for the production of thousands of chemical products ${ }^{33}$, could also be considered.

The solubility of each gas in ILs is checked based on the solubility database 
established in previous work ${ }^{32}$. Together with an extended experimental pure property database and models (given in Tables S1-S2 of the Supporting Information), the feasibility and the potential for industrialization of the selected IL are also analyzed. If the IL does not absorb $\mathrm{CH}_{4}$, then all other gases could be potentially removed and the method needs to identify which gas to remove first. In this case, the solubility of the gas and the selectivity of the gas compared to $\mathrm{CH}_{4}$ in the IL needs to be checked. Also, the boiling points of the gases compared to $\mathrm{CH}_{4}$ needs to be checked. The first gas to be removed should have the highest solubility and selectivity compared to $\mathrm{CH}_{4}$ in IL. For the other gases that could not be absorbed by IL, they can be separated through a series of distillation steps, whose sequence is based on a ranking beginning from the gas with lowest boiling point and going to the highest.

\subsection{IL Screening Method}

The gas solubility and selectivity are quantified through Henry's law constant. However, as the reported Henry's law constant is usually mole-based and the solvent is usually measured on a mass basis, therefore, in this work, the mass-based Henry's law constant, which is the mole-based Henry's law constant multiplied by the molecular mass of IL ( $\mathrm{kg} / \mathrm{mol})$, is considered. The most suitable IL is the one, which has the minimum mass-based Henry's law constant of gas and high selectivity of gas $/ \mathrm{CH}_{4}$. In addition, judging a solvent's potential for industrial application, the following pure component properties are also considered: viscosity, which affects the absorption capacity of solvent as well as the fluidity in process, normal melting point, 
making sure that the solvent is liquid at the operation condition ${ }^{34}$. It should be noted, however, these pure component properties may not be available for the selected IL based on solubility and selectivity alone. Therefore, it is useful to also have an option for model-based IL screening.

The IL screening method has two options; a) practical IL screening based on the experimental database to identify any IL for which the needed gas solubility data and experimental pure property of the IL are available; b) computer-aided additional IL design option using a predictive thermodynamic model (UNIFAC-IL), which have been developed in our previous work ${ }^{32}$ together with a suite of verified GC-based pure component property models. The collected set of pure component property prediction models are listed in Table S2 of Supporting Information as part of the pure property model library. These models are required such that unavailable pure properties of ILs with good separation potential could be further considered in the next stages. The objective of the model-based option-b is to systematically design a potentially superior IL that may provide the incentive for further studies on its future synthesis, development and application. In this work, both options are developed and the two best ILs from each option are further investigated below.

\subsubsection{Option- $a$}

For the model shale gas components. $\mathrm{H}_{2}$ is almost not soluble in ILs ${ }^{35}$. Henry's law constant of $\mathrm{CO}_{2}$ and three gases $\left(\mathrm{CH}_{4}, \mathrm{C}_{2} \mathrm{H}_{4}, \mathrm{C}_{2} \mathrm{H}_{6}\right)$ in ILs are retrieved from the database. Experimental data of mass-based Henry's law constant of gas and selectivity of gas to $\mathrm{CH}_{4}$ in different ILs are retrieved and the comparison of their values is 
shown in Figure.2. Measured pure component properties (such as viscosity, density) of the ILs are collected and added as an extension to the database (given in Table S1 in Supporting Information), which not only helps to check if all necessary data for a potentially promising IL is available, but also helps to identify a solvent with relative low viscosity.

From Figure 2, it is observed that with increasing temperature, both the gas solubility and the selectivity decreases. All the data in Figure 2 are divided into 4 regions: bottom-left, bottom-right, top-left, top-right. The ILs located at the top-left region under room temperature are considered to be potentially attractive because they have acceptable solubility (note that in Figure 2, the solubility is the inverse of the plotted value on the x-axis) and selectivity. Therefore, the ILs from the top-left region have the necessary solubility and selectivity properties to be Next, we check if the experimental pure component properties are available in Table S1 for these selected ILs. The ILs with available data that matches the requirements of low viscosity, etc., could be regarded as potential candidates suitable for investigation in stages $2 \& 3$. The ILs that have acceptable solubility data, such as [amim][dca], but for which the necessary measured pure component properties are not available, they are selected for consideration in option-b, where the missing properties would be estimated through available models. However, since none of these ILs are found to have significantly better solubility of $\mathrm{CO}_{2}$ and selectivity of $\mathrm{CO}_{2} / \mathrm{CH}_{4}$ than the selected IL, they are discarded. IL-a, [thtdp][phos], (see Figure 3 for the IL structure details), with the minimum Henry's law constant, relatively high selectivity and 
available measured pure component properties in the database, is selected as the most appropriate IL for absorption of $\mathrm{CO}_{2}$ from $\mathrm{CH}_{4}$. This result is consistent with that reported by Ramdin et al. ${ }^{36}$. In addition, $\mathrm{C}_{2} \mathrm{H}_{4}$ and $\mathrm{C}_{2} \mathrm{H}_{6}$ are also contained in remaining shale gas, therefore, the solubilities of $\mathrm{C}_{2} \mathrm{H}_{4}$ and $\mathrm{C}_{2} \mathrm{H}_{6}$ in the selected IL-a are checked respectively through the estimated properties from the corrected COSMO-RS (since measured data are not available) and found to be much lower than that of $\mathrm{CO}_{2}$ in option-b (seen in Figure $2 b$ and $2 c$ ). Then, [thtdp][phos] is regarded as the best-known IL selected from available data for $\mathrm{CO}_{2}$ removal from the model shale gas considered in this work. Then the rest gases are separated further through traditional distillation.

\subsubsection{Option- $b$}

In addition to the UNIFAC-IL model and corrected COSMO-RS model established in previous work ${ }^{32}$, some pure component property models for IL are collected (listed in Table S2 of Supporting Information). As stated in section 2, this option should be used to design a significantly better IL than what can be found from option-a as well as complete the missing properties for an IL that looks promising in option-a. In this work, in order to find a better IL for the specific gas absorption, we specify stricter constraints on the pure component properties (Eq.1-2) than that in IL-a to find an IL that is placed higher than IL-a in the top-left region of Figure 2.

$$
\begin{aligned}
& T_{m}<298.5(K) \\
& \eta<0.1(\mathrm{~Pa} \cdot \mathrm{S})
\end{aligned}
$$

The Henry's law constant of $\mathrm{CO}_{2}$ and other 3 light hydrocarbon gases in ILs 
comprised of different groups are calculated based on the UNIFAC-IL model established in our previous work for the activity coefficient of shale gas components in common ILs. The groups having parameter with both $\mathrm{CO}_{2}$ and $\mathrm{CH}_{4}$ are used. It contains 2 substituents, 2 kinds of cations and 7 anions as molecular building blocks, as given in Table S3 of Supporting Information. In the computer-aided IL design, various functional cations, anions and substituents are combined systematically based on certain structural constraints to generate feasible ILs with desired properties. Detailed information for IL design in GAMS is given in Table S4 of the Supporting Information. Similar to option-a, no solvent could be found with acceptable solubility and selectivity for absorbing $\mathrm{C}_{2} \mathrm{H}_{4}$ and $\mathrm{C}_{2} \mathrm{H}_{6}$. Then minimization of mass-based $\mathrm{H}_{\mathrm{CO}_{2}}$ (Eq. 3) with a higher selectivity (Eq. 4) than IL-a is considered as the optimal target in this computer-aided IL design problem. The IL having better properties than IL-a, that is, pyridinium based IL ([MMpy][eFAP] (IL-b): 1,3-dimethylpyridinium tris(pentafluoroethyl) trifluorophosphate), has been found (see Figure 4). This IL-b has almost three times higher selectivity than IL-a. As seen in Figure 2a, the point of IL-b falls right in the top corner of the top-left region and also has low solubility for $\mathrm{C}_{2} \mathrm{H}_{4}$ and $\mathrm{C}_{2} \mathrm{H}_{6}$ gases as shown in Figures $2 \mathrm{~b}$ and $2 \mathrm{c}$, indicating a much better separation property.

$$
\begin{aligned}
& H_{i}=M_{I L} P_{i}^{s a t} \gamma_{i}{ }^{\infty} \\
& H_{C_{4}} / H_{C_{2}} \geq 15
\end{aligned}
$$


Where, $M_{I L}$ is the molar mass of ionic liquid, $\gamma_{i}{ }^{\infty}$ is the infinite dilution activity coefficient of component $i$, obtained from UNIFAC-IL model, $P_{i}^{s a t}$ is the saturated pressure of component $i . T_{m}$ is the melting point of IL and $\eta$ is the viscosity of IL.

\section{Process Design and Simulation}

\subsection{Process Design}

As stated in section 3.1, the gas separation process consists of an absorption step followed by two distillation (or hybrid distillation-membrane) steps. Thus, the total gas separation process consists of two main parts; $\mathrm{CO}_{2}$ removal and light hydrocarbon gas separation. As illustrated in Figure 5, the $\mathrm{CO}_{2}$ removal section consists of an absorption column followed by a series of depressurized flash vessels. To ensure a high $\mathrm{CO}_{2}$ recovery rate, a vacuum pressure (around 0.5 bar) is fixed for the last flash vessel, from which, the recovered IL solvent is recycled to the top of the absorber.

\subsection{Preparation of Thermodynamic Models}

Process simulation and assessment are essential for any process design before it is implemented in the industry. Due to the shortage of rigorous thermodynamic models for complex IL-containing systems in process simulators, ILs are created as pseudo components and added to their databases. Therefore, before simulations could be made, the thermodynamic models for the selected ILs ([thtdp][phos] and [MMpy][eFAP]) need to be established. The models include three parts: single value pure component properties (critical properties, normal melting points, viscosities, densities, etc.), temperature-dependent functional pure component properties, composition and temperature-dependent mixture functional properties. 


\subsubsection{Single Value Pure Component Properties}

Critical properties together with the normal melting point are needed as they are used in many corresponding state correlations for volumetric and thermodynamic properties of ILs. The normal melting point is estimated based on a group contribution model developed by Lazzús et al. ${ }^{37}$, the group parameters for ILs are regressed in our previous work ${ }^{19}$ (given in Table S2 of the Supporting Information). There are several studies on how critical properties for ILs can be estimated. Valderamma and Robles ${ }^{38}$ used a method to estimate the critical properties of 200 ionic liquids using 26 groups. The results show good consistency in determining the density of the ILs. Considering the selected two ILs ([thtdp][phos], [MMpy][eFAP]) (structure seen in Figures 3 and 4), which we will use for the $\mathrm{CO}_{2}$ removal step, they can be divided into, respectively, 6 groups $\left(-\mathrm{CH}_{3},-\mathrm{CH}_{2^{-}},>\mathrm{CH}-,-\mathrm{O}-,-\mathrm{P}\right)$ and 7 groups $\left(-\mathrm{CH}_{3},=\mathrm{CH}-,>\mathrm{CH}=,>\mathrm{C}<\right.$, $[>\mathrm{N}=]+,-\mathrm{F},-\mathrm{P})$ according to Valderamma's work. The same method is applied for estimating the critical property of [thtdp][phos] and [MMpy][eFAP]. The relevant equations, estimated critical property values and the verification results can be found in Eqs.S1-S6, Table S2 and Figure S1, respectively, of the Supporting Information.

\subsubsection{Temperature-Dependent Functional Pure Component Properties}

Several temperature-dependent pure component properties are required in the process simulation. In the simulator chosen (Aspen Plus), these properties are estimated using Eqs. 5-9 listed in Table 2. The equation coefficients used for the two ILs are given in Table S5 of the Supporting Information. They are obtained from experimental data and group contribution models developed in our previous work ${ }^{19}$ 
using the objective function of Eq. 10. Detailed verification results are shown in Figure S2 of the Supporting Information.

$$
O b j=\sum_{i=1}^{N P}\left(\frac{X_{i, \exp }-X_{i, c a l}}{X_{i, \exp }}\right)^{2}
$$

\subsubsection{Composition and Temperature Dependent Mixture Functional Properties}

In Aspen Plus, the phase equilibrium relationship for the dissolved gases is:

$$
\begin{gathered}
\varphi_{i}^{V} y_{i} p=x_{i} \gamma_{i}^{*} H_{i A} \\
\gamma_{i}^{*}=\gamma_{i} / \gamma_{i}^{\infty}
\end{gathered}
$$

Where $p, y_{i}$, and $x_{i}$ are the total pressure, the mole fraction of component $i$ in vapor phase and liquid phase, respectively, $\varphi_{i}^{V}$ is the fugacity coefficient in the vapor phase, which can be obtained by the Soave-Redlich-Kwong (S-R-K) equation of state, related parameters can be found in Table S6 and S7 of Supporting Information. $H_{i A}$ is Henry's law constant of component $i$ in solvent A.

Henry's law constant is calculated using the following temperature-dependent equation:

$$
\ln H_{i A}(\text { bar })=a_{i A}+b_{i A} /_{T}+c_{i A} \ln T+d_{i A} T
$$

where $a_{i A}, b_{i A}, c_{i A}, d_{i A}$ are the equation parameters. For the gas-IL systems in this work, the values are listed in Tables S8 of Supporting Information.

The activity coefficient of gas in IL is modeled by the NRTL just for the simulation part. 


$$
\ln \gamma_{i}=\frac{\sum_{j=1}^{n} x_{j} \tau_{j i} G_{j i}}{\sum_{k=1}^{n} x_{k} G_{k i}}+\sum_{j=1}^{n}\left(\frac{x_{j} G_{i j}}{\sum_{k=1}^{n} x_{k} G_{k j}}\left(\tau_{i j}-\frac{\sum_{m=1}^{n} x_{m} \tau_{m j} G_{m j}}{\sum_{k=1}^{n} x_{k} G_{k j}}\right)\right)
$$

where $G_{j i}=\exp \left(-\alpha_{j i} \tau_{j i}\right), \tau_{j i}=a_{i j}+b_{i j} / T, \alpha_{j i}=\alpha_{i j}, n$ is the number of components; $x$ is the mole fraction; $R$ is gas constant; $T$ is the absolute temperature; and $G_{i j}$ is a dimensionless interaction parameter; $a_{i j}$ and $b_{i j}$ are the binary parameters which are regressed in this work and the values are listed in Tables S9 of Supporting Information; $\alpha_{i j}$ is the nonrandomness factor which can be fixed at 0.3 used for most polar systems.

\subsection{Phase Equilibrium Calculation Results}

Among the components of the model shale gas, $\mathrm{H}_{2}$ is almost not soluble in IL, associated binary parameters are set to be very small to obtain a zero value of the solubility. As a result, the binary interactions in this work include four systems: $\mathrm{CO}_{2}$-IL, $\mathrm{CH}_{4}$-IL, $\mathrm{C}_{2} \mathrm{H}_{4}$-IL and $\mathrm{C}_{2} \mathrm{H}_{6}$-IL. For $\mathrm{CO}_{2}$ and $\mathrm{CH}_{4}$, the measured Henry's law constant and solubility data in [thtdp][phos] are retrieved from the database referred in literature ${ }^{7,36}$. For $\mathrm{C}_{2} \mathrm{H}_{4}$ and $\mathrm{C}_{2} \mathrm{H}_{6}$ in [thtdp][phos] and the gases in the other IL ([MMpy][eFAP]), as stated in section 3.2, the corrected COSMO-RS model together with the UNIFAC-IL model, proposed from our previous work ${ }^{32}$, have been applied to obtain the virtual-measured Henry's law constant and solubility data, which are used further in the simulations. Henry's law constant can be obtained from the calculated activity coefficients and the saturated vapor pressure (see Eq. 3).

Figure. 6 shows the comparison of measured data with the calculated values for IL-a. It shows that the model results agree well with the measured data having an AARD (average absolute relative deviation) of $3 \%$ and $9 \%$, respectively, for $\mathrm{CO}_{2}$ and $\mathrm{CH}_{4}$. 
This good agreement indicates the reliability of the thermodynamic model in process simulation used for IL-a.

The calculated solubility results of all gases in both ILs using Aspen are shown in Figure.7. It can be seen that the solubility of $\mathrm{CO}_{2}$ in the two ILs is similar but the solubility of $\mathrm{CH}_{4}$ in [MMpy][eFAP] is much smaller than that in [thtdp][phos]. This means that a higher selectivity of $\mathrm{CO}_{2} / \mathrm{CH}_{4}$ is found in [MMpy][eFAP], almost three times higher than that of [thtdp][phos]. This result is consistent with the values obtained at the IL screening stage, demonstrating the reliability of the thermodynamic model used for IL-b.

\subsection{Process Simulation}

\subsubsection{Gas Separation Measurement}

The process simulation for the shale gas separation is divided into two main parts: $\mathrm{CO}_{2}$ removal and light hydrocarbon gas separation. In order to evaluate the process separation performance, the $\mathrm{CO}_{2}$ removal rate in absorber, gas purification (Vol\%) of each gas stream and the gas recovery rate are considered using the following equations.

$$
\begin{gathered}
\text { Removal }_{\text {gas }}=1-\frac{\text { mole } / \text { mass } \text { flow of } X \text { in gasout stream top in absorber }}{\text { mole } / \text { mass flow of } X \text { in feedgas stream }} \times 100 \% \\
\text { Recovery }_{\text {gas }}=\frac{\text { mole } / \text { mass } \text { flow of } X \text { out of related } X \text { stream }}{\text { mole } / \text { mass flow of } X \text { in feedgas stream }} \times 100 \%
\end{gathered}
$$

\subsubsection{Sensitivity analysis of key operation parameters}

Consumption of IL and stage numbers in absorber: The influence of solvent consumption on the absorbed rate of $\mathrm{CO}_{2}$ is shown in Figure.8. In order to evaluate 
the separation capacity under different stages of the absorber, the $\mathrm{CO}_{2}$ absorbed rate at each different stage number in the absorber is calculated based on Eq. 15. As seen from Figure.8, with increasing IL amount and stage number, more $\mathrm{CO}_{2}$ can be absorbed, but the IL amount plays a more important role by removing most of $\mathrm{CO}_{2}$. As a result, the stage number of absorber is set to 10 . The remaining shale gas can fulfill requirement $(<\mathrm{Vol} 3 \%)$ of $\mathrm{CO}_{2}$ content in commercial gas. The comparison of the two IL-based absorption processes shows that the IL amount required for a $100 \%$ removal is different. Less amount of IL-a ([thtdp][phos]) is needed under the same $\mathrm{CO}_{2}$ removal rate because of a 0.25 -times-higher solubility than that in IL-b. However, in addition to the selectivity, IL-b shows better performance on other pure component properties for the application, such as a much lower value in viscosity and heat capacity. Considering that more than $95 \% \mathrm{CO}_{2}$ has been absorbed, the solvent amount is determined to be 630 ton/h for [thtdp][phos] and 750 ton/h for [MMpy][eFAP]. According to another research for IL-based $\mathrm{CO}_{2}$ removal work ${ }^{31}$ (72 ton/h IL used to purify the biogas containing $390 \mathrm{~kg} / \mathrm{h} \mathrm{CO}$ in the feed gas), the amount of IL used in this work is reasonable.

Desorption pressure of flash: Being a physical solvent-based process, the $\mathrm{CO}_{2}$ is usually desorbed through a series of 3 flashes with decreasing pressures. The pressure is determined based on the mass flow of $\mathrm{CO}_{2}$ coming out of the last flash. Figure.9 shows the influence of the pressure of first flash (flash-1) on the mass flow of $\mathrm{CO}_{2}$ out of the system for the two different IL-based processes. The stream coming out of the absorber has a high pressure which is 30 bar. It is found that the $\mathrm{CO}_{2}$ recovery out of 
the last flash decreases rapidly when the pressure decreases to around 8 bar. This implies that a large decrease of the pressure in the first flash would lead to a lower $\mathrm{CO}_{2}$ recovery rate with a large amount of gas going back to the absorber. Then, the pressure of flash-1 for [thtdp][phos] and [MMPy][eFAP] is set to 20 bar and 14 bar, respectively. Similarly, for flash-2, to keep a high recovery rate of $\mathrm{CO}_{2}$, the pressure is determined to be 8 bar, 12 bar, respectively for the [thtdp][phos] and [MMpy][eFAP] based processes.

For the last flash-3, vacuum pressure is employed to obtain a high recovery rate of $\mathrm{CO}_{2}$. As seen in Figure 10, when the pressure is set to 0.5 bar, for the [thtdp][phos] based process, $90 \%$ recovery rate of $\mathrm{CO}_{2}$ could be achieved, but for the [MMpy][eFAP] based process, a lower pressure is needed ( 0.25 bar $)$.

Key parameters of the distillation columns: Due to the close boiling points of $\mathrm{C}_{2} \mathrm{H}_{4}$ and $\mathrm{C}_{2} \mathrm{H}_{6}$ (see data given in Table 1), more stages and also higher reflux ratio are needed in D2. Detailed key parameters of the two columns after separation optimization can be found in Table S10 of the Supporting Information. Besides, as other hybrid process schemes for these gas separation have been reported ${ }^{43,44}$, they are not investigated in detail here. The important issue here is how much $\mathrm{C}_{2} \mathrm{H}_{4}$ and $\mathrm{C}_{2} \mathrm{H}_{6}$ are available and whether an economically feasible scheme for their separation is necessary. Also, it could be that $\mathrm{C}_{2} \mathrm{H}_{4}, \mathrm{C}_{2} \mathrm{H}_{6}$ with a small amount of $\mathrm{CO}_{2}$ could be directly used in synthesis of other higher-value chemicals ${ }^{45}$. Note that the mail fuel product is obtained from the first distillation column quite easily.

\section{Process Evaluation}


The following two processes are simulated: (a) IL-based process with IL-a ([thtdp][phos]) obtained from option-a. (b) IL-based process with IL-b ([MMpy][eFAP]) designed through option-b.

A selection of the simulation results that helps to assess the four gas streams corresponding to gas separation processes for the two ILs are summarized in the Supporting Information Tables S11. Several performance criteria are compared under same gas recovery rate or same purity rate in this section.

\subsection{Energy and Cost Estimation Methodology}

\subsubsection{Energy Consumption Evaluation}

Energy consumption is regarded as a key indicator of any process evaluation, especially for $\mathrm{CO}_{2}$ separation processes. Usually, the total energy consumption (TEC) for a process includes thermal energy and electricity. Then, the total energy is expressed by an equivalent energy penalty ${ }^{5}$, but in the IL-based processes of this work, only electricity is consumed in the three-stage flash vessels without any other heat requirements (not considering the two distillation steps). As a result, the total energy consumption is, in our case, equal to the electricity consumption. To compare with other processes with different raw gas and with other technologies, the specific energy consumption (SEC) is a useful indicator:

$$
\mathrm{SEC}=\frac{T E C}{m_{\text {out }}}
$$

where the units of TEC and SEC are $\mathrm{MJ} / \mathrm{h}, \mathrm{MJ} / \mathrm{kg}$ gas, respectively, $m_{\text {out }}$ is the mass flow of the gas out of the system.

\subsubsection{Economic Evaluation}


The purpose of the economic analysis of the process is to calculate the total removal cost (TRC) which is used to evaluate and compare the two processes. TRC is calculated from the sum of the annualized capital cost (ACC) and total operating expense (OPEX) both of which are computed based on other types of costs, as shown in Table $3^{26,46,47}$. Detailed calculation information can be found in Tables S10-S11 of the Supporting Information.

The annualized capital cost (ACC) can be calculated from translating the total capital expense (CAPEX) into annualized capital investment of the whole project, as in Eq.18. CAPEX is then computed on the basis of Table S12 in the Supporting Information, following Abu-Zahra et al. ${ }^{46}$ and Schach et al. ${ }^{48}$. The purchased equipment cost (PEC) is obtained according to Walas ${ }^{49}$. The size of the equipment is obtained from the simulation in Aspen Plus. All the equipment costs are updated to the year 2018 with the Chemical Engineering Cost Index ${ }^{50}$.

The ACC equation is:

$$
\mathrm{ACC}=\frac{T C I}{\left((1+i r)^{n}-1\right) / i r(1+i r)^{n}}
$$

Where ir denotes the annual interest rate, assuming $8 \%$ in this work, $n$ denotes project lifetime, assuming 25 years ${ }^{26}$.

The total operating expense (OPEX) includes two parts: one is the variable operating cost (VOC) which contains the solvent make-up and the public utilities such as heat steam, cooling water and electricity. The other part is the fixed operating cost (FOC), including the operating labor, maintenance, R \& D cost, etc. Detailed 
calculation methods can be found in Table S13 of Supporting Information. The price of utilities is obtained from literature ${ }^{51-54}$. The price of both ILs is estimated to be $100 \mathrm{k} \$ /$ ton under the assumption of industrial production in the future based on the estimation by Linzhou Keneng Materials Technology Co., Ltd. China ${ }^{26}$. Due to the non-volatility of IL, most of IL is recycled during the process and a little fresh IL is needed. We have assumed $0.35 \mathrm{~g} /$ ton $\mathrm{CO}_{2}$ in this work ${ }^{30}$. As a result, the two processes could be compared under the condition of same unit price in solvent.

\subsection{Process Evaluation Results}

\subsubsection{Energy Consumption}

For the IL-based $\mathrm{CO}_{2}$ removal process in this work, the total energy consumption (TEC) is only consumed through electricity. It is generated from the pump, vacuum pump and compressor for solvent recycle and gas recovery. To make a better comparison, we simulate the two processes under same $\mathrm{CO}_{2}$ recovery rate $(90 \%)$, as seen in Table 4. The TEC for $\mathrm{CO}_{2}$ removal in the two processes are shown in Figure.11. It is found that the IL-b process could achieve a 54\% reduction in TEC compared with the IL-a process. As a result, we can conclude that even though the designed IL-b has somewhat lower solubility than IL-a (leading a high solvent consumption, given in Table 4), the high $\mathrm{CO}_{2} / \mathrm{CH}_{4}$ selectivity results in less gas to be recycled and thus the electricity consumed in compressor (given in Table 4) can be much reduced. The specific energy consumption (SEC) in these two processes are $0.71 \mathrm{MJ} / \mathrm{kg} \mathrm{CO}, 0.33 \mathrm{MJ} / \mathrm{kg} \mathrm{CO}$, respectively for processes using IL-a and IL-b as given in Table 4, indicating a better improvement of using the designed ILb. In 
addition, compared with the SEC in the MDEA process $\left(1.56 \mathrm{MJ} / \mathrm{kgCO}_{2}\right)$ and also in another IL ([bmim] $\left.\left[\mathrm{NTf}_{2}\right]\right)$ based process $\left(0.86 \mathrm{MJ} / \mathrm{kgCO}_{2}\right)$ reported in our previous work ${ }^{5}$, the IL-based process gives an improved energy-based technology.

\subsubsection{Economic Analysis}

For the $\mathrm{CO}_{2}$ removal process, the distribution of total removal cost (TRC) per ton $\mathrm{CO}_{2}$ is shown in Figure 12. Detailed equipment cost results are given in Table S14 of the Supporting Information. It can be observed that the total operating expense (OPEX) occupies more than $90 \%$ of the annualized total removal cost. Even though the high price of IL, the solvent make-up per year is around $1560 \$ / y e a r$ which occupies little of the OPEX. The main utility cost is electricity consumed by the compressor and pump due to gas and solvent recovery. Besides the fixed operating cost (FOC), the variable operating cost (VOC) is the second dominating contributor to the OPEX. This illustrates the importance of reducing total energy consumption. Compared with the IL-a process, the higher selectivity of $\mathrm{CO}_{2} / \mathrm{CH}_{4}$ in IL-b process gives a reduction of $54 \%$ and $30 \%$, respectively for electricity cost and TRC of per ton $\mathrm{CO}_{2}$ removal. Additionally, compared with the conventional amine-based processes reported by other researchers in total cost (for instance, 55\$/ton $\mathrm{CO}_{2}$ by Hassan et al. ${ }^{55}, 74 € /$ ton $\mathrm{CO}_{2}$ by Raynal et al. ${ }^{56}, 112 \$ /$ ton $\mathrm{CO}_{2}$ by Mores et al. ${ }^{52}$ and $70 \$ /$ ton $\mathrm{CO}_{2}$ by Huang et al. $\left.{ }^{26}\right)$, the designed IL-b process cost $\left(38 \$ /\right.$ ton $\left.\mathrm{CO}_{2}\right)$ is lower, demonstrating the important effect of the selectivity property of a solvent on the whole process. The cost for IL-a process $\left(54 \$ /\right.$ ton $\left.\mathrm{CO}_{2}\right)$ is similar to the above-reported costs for traditional technology. Both these two processes indicate a 
promising cost-efficient technology for IL-based $\mathrm{CO}_{2}$ removal.

For the light hydrocarbon gas separation, as given in Table 4, two high-purity streams $\left(\mathrm{CH}_{4}\right.$ and $\mathrm{C}_{2} \mathrm{H}_{6}$ gas streams with more than Vol 96\%) could be obtained as two commercial products in both the IL-based processes. Some performance criteria are compared under the same gas purity rate. Detailed equipment cost can be found in Table S14 of the Supporting Information.

The utility applied in the distillation columns to produce each gas and the total cost of the whole separation process to produce per ton gas are calculated and shown in Table 4. It is found that the utility cost to produce light hydrocarbon gases in the two distillation columns in IL-b process is slightly lower than that in IL-a process. This is because the higher selectivity of $\mathrm{CO}_{2}$ to other gases in IL-b, leading much more light hydrocarbon gases that come out from top of the absorber in the IL-b process than that in IL-a process. Similarly, combined with the lower cost in $\mathrm{CO}_{2}$ removal process, the total cost for these two gas production processes could be reduced much more in IL-b process than in IL-a process, especially for $\mathrm{C}_{2} \mathrm{H}_{6}$. However, considering the higher recovery rate of $\mathrm{CH}_{4}, \mathrm{C}_{2} \mathrm{H}_{6}$ and lower total cost for $\mathrm{CO}_{2}$ removal, the designed IL-b process points to a better choice than the IL-a process. According to the price of commercial $\mathrm{CH}_{4}\left(\sim 2400 \$ /\right.$ tonCH$\left._{4}{ }^{57}\right)$, this further light hydrocarbon gas separation has the potential to achieve a good profit. Note also that additional energy could be reduced through the use of other hybrid technologies for the light hydrocarbon gases separation such as combined with membrane ${ }^{43}$ or adsorption processes, which is a topic for future consideration. 


\section{Conclusion}

This work proposes a hybrid IL-based technology for the gas separation process where the IL is used to remove the gas in small amount to obtain the desired final products. A three-stage methodology, in which systematic IL screening, process design and simulation, and process evaluation, is established. Extended database and property prediction model library are made available for the 3 stages of the methodology. The screening stage (first stage) offers two options for IL screening: screening based on database (option-a) and model library (option-b), in which option-b could be used as a backup if no suitable IL could be found through option-a. However, if neither option gives an acceptable IL, then there is need for models of wider application range and more research. The use of different property models for the overall goal of development of reliable $\mathrm{CO}_{2}$ removal technologies from shale gases is highlighted. That is, the COSMO-RS model is used to generate pseudo-experimental data needed for developing the GC based models (UNIFAC-IL). Then the UNIFAC-IL model is applied for process synthesis-design, where a larger search space is necessary. For a greater search space, use of predictive models such as UNIFAC-IL has an advantage. However, for the verification by simulation, a third model, the NRTL model, which is good for a specific chemical system, has been used. Clearly, for a successful and wider application of the methodology, further extension of database and IL design models are needed.

For the model shale gas considered, two ILs are selected through the two options: IL-a ([thtdp][phos]) is identified through an experimental database while IL-b, 
([MMpy][eFAP]) is obtained using a model-based option (UNIFAC-IL) to find additional IL based on Computer-Aided design. Before process simulation could be performed, NRTL and Henry's law constant models for the related IL-gas systems and IL pure property predicted models are established in ASPEN-Plus, the selected process simulator. In this work, for the IL-design stage, the predictive UNIFAC-IL model is used, while for verification by simulation, the fitted NRTL model is used. The calculated solubility data of $\mathrm{CO}_{2}$ and $\mathrm{CH}_{4}$ in IL-a from the established model are in good agreement with the available experimental data. The two IL-based $\mathrm{CO}_{2}$ removal processes followed by distillation for hydrocarbon gas separation are simulated and evaluated in terms of energy consumption and economics. Even though larger amount of IL-b is needed, the higher selectivity of $\mathrm{CO}_{2} / \mathrm{CH}_{4}$ helps to not only obtain a higher purity $\mathrm{CO}_{2}$ gas under the same gas recovery rate, but also achieve a $54 \%$ lower total energy demand, compared with IL-a process, resulting in a lower total removal cost per ton $\mathrm{CO}_{2}$ to around $30 \%$. Economic analysis shows that the operation expense (OPEX) is one of the main contributors to the total removal cost of per ton $\mathrm{CO}_{2}$ separation, showing the importance of reducing the total energy demand. High purity (>Vo196\%) of $\mathrm{CH}_{4}$ and $\mathrm{C}_{2} \mathrm{H}_{6}$ gas streams could be obtained as products with a good profit in both IL-based separation processes, with much better results for IL-b process. As a result, IL-b with its good separation results, designed through option-b, provides a promising recommendation for future solvent development of gas separation process. Future work would focus on further removing the hydrogen for syngas production combining with the removed $\mathrm{CO}_{2}$ as well as separation and use of 
$\mathrm{C}_{2} \mathrm{H}_{4}$ and $\mathrm{C}_{2} \mathrm{H}_{6}$.

\section{Acknowledgments}

This work was financially supported by National Key Projects for Fundamental Research and Development of China (2018YFB0605802), the joint project from Institute of Process Engineering Chinese Academy of Sciences and Department of Chemical and Biochemical Engineering in Technical University of Denmark, the National Natural Science Foundation of China (21838010, 21890764), the DNL Cooperation Fund, CAS (DNL180406), and the Beijing hundreds of leading talents training project of science and technology (Z171100001117154).

\section{Appendix Supporting information}

Supporting information associated with this article can be found in the online version.

\section{Notation}

Symbols

$p_{i}^{s}=$ vapor pressure of pure component $i$

$P=$ pressure, $\mathrm{Pa}$

$T=$ temperature, $\mathrm{K}$

$x_{i}=$ composition of component $i$ in liquid

$y_{i}=$ composition of component $i$ in vapor

$\gamma_{i}=$ activity coefficient

$\gamma_{i}^{\infty}=$ the infinite dilution activity coefficient of component $i$

$H_{i A}=$ Henry's law constant of component $i$ in solvent A, $\mathrm{bar} \cdot \mathrm{kg} / \mathrm{mol}$

$M_{i}=$ is the molar mass of component $i$.

$\eta=$ viscosity, Pa.S.

$V=$ molar volume, $\mathrm{m}^{3} / \mathrm{mol}$. 
$C_{p i}=$ heat capacity of component $i, \mathrm{~J}^{-1} \mathrm{~K}^{-1} \cdot \mathrm{mol}^{-1}$.

$\lambda=$ thermal conductivity, $\mathrm{W} / \mathrm{mK}$.

$\sigma_{f}=$ surface tension in $\mathrm{mN} / \mathrm{m}$.

$\varphi_{i}^{V}=$ fugacity coefficient in the vapor phase.

\section{Abbreviations}

\begin{tabular}{ll} 
IL & Ionic liquid \\
MEA & monoethanolamine \\
MDEA & methyldiethanolamine \\
DEA & diethanolamine \\
[thtdp][phos] & trihexyltetradecylphosphonium bis(2,4,4-trime-thylpentyl)phosphinate) \\
[MMpy][eFAP] & 1,3-dimethylpyridinium tris(pentafluoroethyl) trifluorophosphate \\
EoS & equation of state \\
COSMO-RS & conductor-like screening model for real solvents \\
UNIFAC & universal quasichemical functional-group activity coefficient \\
NRTL & non-random two liquid \\
AARD & average absolute relative deviation \\
TEC & total energy consumption \\
SEC & specific energy consumption \\
TRC & total removal cost \\
ACC & annual capital cost \\
OPEX & total operating expense \\
CAPEX & total capital expense \\
PEC & purchased equipment cost \\
VOC & variable operating cost \\
FOC & fixed operating cost \\
\hline
\end{tabular}

\section{References}

1. Ehlinger, V.M., K.J. Gabriel, M.M.B. Noureldin, and M.M. El-Halwagi, Process Design and Integration of Shale Gas to Methanol. ACS Sustainable Chemistry \& Engineering, 2014. 2: 
30-37.

2. He, C. and F. You, Shale Gas Processing Integrated with Ethylene Production: Novel Process Designs, Exergy Analysis, and Techno-Economic Analysis. Industrial \& Engineering Chemistry Research, 2014. 53: 11442-11459.

3. Hill, R.J., D. M.Jarvie, J. Zumberge, M. Henry, and R.M. Pollastro, Oil and Gas Geochemistry and Petroleum Systems of the Fort Worth Basin. AAPG Bulletin, 2007. 91: 445-473.

4. !!! INVALID CITATION !!! 4-6.

5. Liu, X., Y. Huang, Y. Zhao, R. Gani, X. Zhang, and S. Zhang, Ionic Liquid Design and Process Simulation for Decarbonization of Shale Gas. Industrial \& Engineering Chemistry Research, 2016. 55: 5931-5944.

6. Blanchard, L.A., D. Hancu, E.J. Beckman, and J.F. Brennecke, Green Processing using lonic Liquids and $\mathrm{CO}_{2}$. Nature, 1999. 399: 28-29.

7. Ramdin, M., A. Amplianitis, S. Bazhenov, A. Volkov, V. Volkov, T.J.H. Vlugt, and T.W.d. Loos, Solubility of $\mathrm{CO}_{2}$ and $\mathrm{CH}_{4}$ in lonic Liquids: Ideal $\mathrm{CO}_{2} / \mathrm{CH}_{4}$ Selectivity. Ind. Eng. Chem. Res., 2014. 53: 15427-15435.

8. Wang, J., C. Petit, X. Zhang, and A.-H.A. Park, Simultaneous measurement of CO2 sorption and swelling of phosphate-based ionic liquid. Green Energy \& Environment, 2016. 1: 258-265.

9. Revelli, A.-L., F. Mutelet, and J.-N. Jaubert, High Carbon Dioxide Solubilities in Imidazolium-Based Ionic Liquids and in Poly(ethyleneglycol) DImethyl Ether. J. Phys. Chem. B, 2010. 114: 12908-12913.

10. Brown, P., B.E. Gurkan, and T.A. Hatton, Enhanced gravimetric CO2 capacity and viscosity for ionic liquids with cyanopyrrolide anion. AIChE Journal, 2015. 61: 2280-2285.

11. Zhang, J., C. Jia, H. Dong, J. Wang, X. Zhang, and S. Zhang, A Novel Dual Amino-Functionalized Cation-Tethered Ionic Liquid for CO2 Capture. Ind. Eng. Chem. Res., 2013. 52: 5835-5841.

12. Zhang, X., X. Zhang, H.D. Dong, Z. Zhao, S. Zhang, and Y. Huang, Carbon capture with ionic liquids: overview and progress. Energ. Environ. Sci., 2012. 5: 6668-6681.

13. Zeng, S., X. Zhang, L. Bai, X. Zhang, H. Wang, J. Wang, . . . S. Zhang, Ionic-Liquid-Based CO2 Capture Systems: Structure, Interaction and Process. Chem Rev, 2017. 117: 9625-9673.

14. Lei, Z., C. Dai, and B. Chen, Gas Solubility in Ionic Liquids. Chem Rev, 2014. 114: 1289-1326.

15. Mota Martinez, M.T., M.C. Kroon, and C.J. Peters, Modeling CO2 solubility in an ionic liquid: $A$ comparison between a cubic and a group contribution EoS. The Journal of Supercritical Fluids, 2015. 101: 54-62.

16. Hizaddin, H.F., M.K. Hadj-Kali, I.M. AlNashef, F.S. Mjalli, and M.A. Hashim, Prediction of CO2 solubility in ionic liquids using the PSRK model. The Journal of Supercritical Fluids, 2015. 100: 184-193.

17. Mortazavi-Manesh, S., M.A. Satyro, and R.A. Marriott, Screening lonic Liquids as Candidates for Separation of Acid Gases: Solubility of Hydrogen Sulfide, Methane, and Ethane. AIChE Journal, 2013. 59: 2993-3005.

18. Lei, Z., C. Dai, W. Wang, and B. Chen, UNIFAC model for ionic liquid-CO2 systems. AIChE Journal, 2014. 60: 716-729.

19. Chen, Y., G.M. Kontogeorgis, and J.M. Woodley, Group-contributed estimation method for properties of ionic liquids. Ind. Eng. Chem. Res., 2019. 58: 4277-4292.

20. Valderram, J.O. and R.E. Rojas, Critical Properties of lonic Liquids. Revisited. Ind. Eng. Chem. Res., 2009. 48: 6890-6900. 
21. Zhou, T., J. Wang, K. McBride, and K. Sundmacher, Optimal design of solvents for extractive reaction processes. AIChE Journal, 2016. 62: 3238-3249.

22. Zhou, T., Y. Zhou, and K. Sundmacher, A hybrid stochastic-deterministic optimization approach for integrated solvent and process design. Chemical Engineering Science, 2017. 159: 207-216.

23. Nocon, G., U. Weidlich, J. Gmehling, J. Menke, and U. Onken, Prediction of gas solubilities by a modified UNIFAC equation. Zeitschrift Fã1/4r Elektrochemie Berichte Der Bunsengesellschaft Fã1/4r Physikalische Chemie, 1983. 13: 381-392.

24. Song, Z., C. Zhang, Z. Qi, T. Zhou, and K. Sundmacher, Computer-aided design of ionic liquids as solvents for extractive desulfurization. AIChE Journal, 2018. 64: 1013-1025.

25. Valencia-Marquez, D., A. Flores-Tlacuahuac, and L. Ricardez-Sandoval, Technoeconomic and Dynamical Analysis of a $\mathrm{CO}_{2}$ Capture Pilot-Scale Plant Using lonic Liquids. Ind. Eng. Chem. Res., 2015. 54: 11360-11370.

26. Huang, Y., X. Zhang, X. Zhang, H. Dong, and S. Zhang, Thermodynamic Modeling and Assessment of Ionic Liquid-Based CO2Capture Processes. Ind. Eng. Chem. Res., 2014. 53: 11805-11817.

27. Eisinger, R.S. and G.E. Keller, Process for $\mathrm{CO}_{2}$ Capture Using lonic Liquid That Exhibits Phase Change. Energy \& Fuels, 2014. 28: 7070-7078.

28. Valencia-Marquez, D., A. Flores-Tlacuahuac, and L. Ricardez-Sandoval, A controllability analysis of a pilot-scale CO2 capture plant using ionic liquids. AIChE Journal, 2016. 62: 3298-3309.

29. Shiflett, M.B., D. W.Drew, R. A.Cantini, and A.Yokozeki, Carbon Dioxide Capture using lonic Liquid 1-Butyl-3-methylimidazolium Acetate. Energ. Fuel., 2010. 24: 5781-5789.

30. Ma, T., J. Wang, Z. Du, A.A. Abdeltawab, A.M. Al-Enizi, X. Chen, and G. Yu, A process simulation study of $\mathrm{CO} 2$ capture by ionic liquids. International Journal of Greenhouse Gas Control, 2017. 58: 223-231.

31. Xu, Y., Y. Huang, B. Wu, X. Zhang, and S. Zhang, Biogas upgrading technologies: Energetic analysis and environmental impact assessment. Chinese J. Chem. Eng., 2015. 23: 247-254.

32. Liu, X., T. Zhou, X. Zhang, S. Zhang, X. Liang, R. Gani, and G.M. Kontogeorgis, Application of COSMO-RS and UNIFAC for ionic liquids based gas separation. Chemical Engineering Science, 2018. 192: 816-828.

33. Siirola, J.J., The impact of shale gas in the chemical industry. AIChE Journal, 2014. 60: 810-819.

34. Chen, Y., G.M. Kontogeorgis, and J.M. Woodley, Integrated ionic liquid and process design involving azetropic separation processes. Chemical Engineering Science, 2019. 203: 402-414.

35. Kumełan, J., Á. Pérez-Salado Kamps, D. Tuma, and G. Maurer, Solubility of H2 in the ionic liquid [hmim][Tf2N]. Journal of Chemical \& Engineering Data, 2006. 51: 1364-1367.

36. Ramdin, M., T.Z. Olasagasti, T.J.H. Vlugt, and T.W. de Loos, High pressure solubility of CO2 in non-fluorinated phosphonium-based ionic liquids. The Journal of Supercritical Fluids, 2013. 82: 41-49.

37. Lazzús, J.A., A group contribution method to predict the melting point of ionic liquids. Fluid Phase Equilibria, 2012. 313: 1-6.

38. Valderamma, J.O., W.W. Sanga, and J.A. Lazzus, Critical Properties, Normal Boiling Temperature, and Acentric Factor of Another 200 lonic Liquids. Ind. Eng. Chem. Res., 2008. 47: 
1318-1330.

39. Campbell, S.W. and G. Thodos, Rackett model-Saturated Liquid Densities of Polar and Nonpolar Pure Substances. Ind. Eng. Chem. Fundam., 1984. 23: 500-510.

40. Ferreira, A.G.M., P.N. Simões, A.F. Ferreira, M.A. Fonseca, M.S.A. Oliveira, and A.S.M. Trino, Transport and thermal properties of quaternary phosphonium ionic liquids and IoNanofluids. The Journal of Chemical Thermodynamics, 2013. 64: 80-92.

41. Neves, C.M.S.S., P.J. Carvalho, M.G. Freire, and J.A.P. Coutinho, Thermophysical properties of pure and water-saturated tetradecyltrihexylphosphonium-based ionic liquids. The Journal of Chemical Thermodynamics, 2011. 43: 948-957.

42. Almeida, H.F.D., J.A. Lopes-da-Silva, M.G. Freire, and J.A.P. Coutinho, Surface tension and refractive index of pure and water-saturated tetradecyltrihexylphosphonium-based ionic liquids. The Journal of Chemical Thermodynamics, 2013. 57: 372-379.

43. Tula, A.K., B. Befort, N. Garg, K.V. Camarda, and R. Gani, Sustainable process design \& analysis of hybrid separations. Computers \& Chemical Engineering, 2017. 105: 96-104.

44. Hosseinpour, S., S. Fatemi, Y. Mortazavi, M. Gholamhoseini, and M.T. Ravanchi, Performance of CaX Zeolite for Separation of $\mathrm{C} 2 \mathrm{H} 6, \mathrm{C} 2 \mathrm{H} 4$, and CH4by Adsorption Process; Capacity, Selectivity, and Dynamic Adsorption Measurements. Separation Science and Technology, 2010. 46: 349-355.

45. Shen, Z., J. Liu, H. Xu, Y. Yue, W. Hua, and W. Shen, Dehydrogenation of ethane to ethylene over a highly efficient Ga2O3/HZSM-5 catalyst in the presence of CO2. Applied Catalysis A: General, 2009. 356: 148-153.

46. Abu-Zahra, M.R.M., J.P.M. Niederer, P.H.M. Feron, and G.F. Versteeg, CO2 capture from power plants: Part II. A parametric study of the economical performance based on mono-ethanolamine. International Journal of Greenhouse Gas Control, 2007. 1: 135-142.

47. Schach, M.O., R.D. Schneider, H. Schramm, and J.U. Repke, Techno-Economic Analysis of Postcombustion Processes for the Capture of Carbon Dioxide from Power Plant Flue Gas. Ind.eng.chem.res, 2015. 49: 532-539.

48. Schach, M.-O., R. Schneider, H. Schramm, and J.-U. Repke, Techno-Economic Analysis of Postcombustion Processes for the Capture of Carbon Dioxide from Power Plant Flue Gas. Industrial \& Engineering Chemistry Research, 2010. 49: 2363-2370.

49. Walas, S.M., 20 - COSTS OF INDIVIDUAL EQUIPMENT, in Chemical Process Equipment, S.M. Walas, Editor. 1990, Butterworth-Heinemann: Boston. p. 663-669.

50. Mignard, D., Correlating the chemical engineering plant cost index with macro-economic indicators. Chemical Engineering Research and Design, 2014. 92: 285-294.

51. Karimi, M., M. Hillestad, and H.F. Svendsen, Capital costs and energy considerations of different alternative stripper conFigureurations for post combustion CO2 capture. Chemical Engineering Research and Design, 2011. 89: 1229-1236.

52. Mores, P., N. Rodríguez, N. Scenna, and S. Mussati, CO2 capture in power plants: Minimization of the investment and operating cost of the post-combustion process using MEA aqueous solution. International Journal of Greenhouse Gas Control, 2012. 10: 148-163.

53. Peters, L., A. Hussain, M. Follmann, T. Melin, and M.B. Hägg, CO2 removal from natural gas by employing amine absorption and membrane technology $-A$ technical and economical analysis. Chemical Engineering Journal, 2011. 172: 952-960.

54. Luyben, W.L., Distillation Design and Control Using Aspen ${ }^{T M}$ Simulation. 2013. 
55. Hassan, S.M.N., P.L. Douglas, and E. Croiset, Techno-Economic Study of CO2 Capture from an Existing Cement Plant Using MEA Scrubbing. International Journal of Green Energy, 2007. 4: 197-220.

56. Raynal, L., P.-A. Bouillon, A. Gomez, and P. Broutin, From MEA to demixing solvents and future steps, a roadmap for lowering the cost of post-combustion carbon capture. Chemical Engineering Journal, 2011. 171: 742-752.

57. Shindell, D.T., J.S. Fuglestvedt, and W.J. Collins, The social cost of methane: theory and applications. Faraday Discuss, 2017. 200: 429-451.

\section{Tables:}

Table 1 Raw shale gas component

\begin{tabular}{ccc}
\hline Component & Percent $(\%)$ & Boiling point $\left({ }^{\circ} \mathrm{C}\right)$ \\
\hline $\mathrm{H}_{2}$ & 3 & -252.8 \\
$\mathrm{CH}_{4}$ & 80 & -161.4 \\
$\mathrm{C}_{2} \mathrm{H}_{4}$ & 3 & -103.7 \\
$\mathrm{C}_{2} \mathrm{H}_{6}$ & 7 & -88.6 \\
$\mathrm{CO}_{2}$ & 7 & -78.5 \\
\hline
\end{tabular}

Table 2 Equations of temperature-dependent properties used for the estimation of ILs properties

\begin{tabular}{|c|c|c|c|}
\hline Property & Equation & No. & Ref. \\
\hline liquid volume & $V^{l}=C_{1} \times\left(\mathrm{C}_{2}\right)^{\left[1+\left(1-T_{r}\right)^{27}\right]}$ & $(5)$ & 39 \\
\hline Heat capacity & $C_{p}=C_{1}+C_{2} T+C_{3} T^{2}$ & $(6)$ & 40 \\
\hline Viscosity & $\ln \mu=C_{1}+\frac{C_{2}}{T}+C_{3} \ln T+C_{4} T^{2}+\frac{C_{5}}{T^{2}}$ & (7) & 41 \\
\hline Thermal conductivity & $\lambda=C_{1}+C_{2} T+C_{3} T^{2}+C_{4} T^{3}$ & (8) & 40 \\
\hline Surface tension & $\sigma_{f}=C_{1}\left(1-T_{r}\right)^{\left(\mathrm{C}_{2}+C_{3} T_{r}+C_{4} T_{r}^{2}+C_{5} T_{r}^{3}\right)}$ & (9) & 42 \\
\hline
\end{tabular}

Note: $\mathrm{V}^{1}$ is liquid volume in $\mathrm{m}^{3} / \mathrm{mol}, C_{p}$ is heat capacity in $\mathrm{J} \cdot \mathrm{K}^{-1} \cdot \mathrm{mol}^{-1}, \mu$ is 
viscosity in $\mathrm{Pa} \cdot S, \lambda$ is thermal conductivity in $W / m K, \sigma_{f}$ is the surface tension in $m N / m, T_{r}$ equals to $T / T_{c}$, where $T_{c}$ is a critical temperature of IL.

Table 3 Calculation measures of total removal cost (TRC)

\begin{tabular}{ll}
\hline Cost item & Calculation basis \\
\hline TRC & Total operating expense (OPEX), annualized capital cost (ACC) \\
OPEX & Variable operating cost (VOC), fixed operating cost (FOC) \\
ACC & Total capital expense (CAPEX) \\
CAPEX & Fixed capital investment (FCI), working capital, startup cost, initial \\
FCI & Direct cost (DC), indirect cost (IC) \\
DC, IC & Purchased equipment cost (PEC) with a coefficient of the percentage \\
\hline
\end{tabular}

Table 4 Process evaluation results in the two IL-based processes

\begin{tabular}{ccc}
\hline & IL-a process & IL-b process \\
\hline $\mathrm{CO}_{2}$ recovered from last flash $\left(\mathrm{CO}_{2}\right.$ stream), $\mathrm{kg} / \mathrm{h}$ & 5541.6 & 5548.5 \\
$\mathrm{CO}_{2}$ recovery rate, $\%$ & 90.0 & 90.1 \\
$\mathrm{CO}_{2}$ purity in $\mathrm{CO}_{2}$ stream, $\%$ & 50.0 & 61.0 \\
Solvent needed, $\mathrm{kg} / \mathrm{kg} \mathrm{CO} \mathrm{CO}_{2}$ & 81.5 & 131.3 \\
Total equivalent energy penalty, $\mathrm{GJ} /$ ton $\mathrm{CO}_{2}$ & 0.7 & 0.3 \\
Electricity cost for $\mathrm{CO}_{2}$ removal process, $\$ /$ ton $\mathrm{CO}_{2}$ & 19.8 & 9.1 \\
Total cost for $\mathrm{CO}_{2}$ removal process, $\$ /$ ton $\mathrm{CO}_{2}$ & 54.0 & 37.8 \\
$\mathrm{CH}_{4}{\text { purity in } \mathrm{CH}_{4} \text { stream, } \mathrm{Vol} \%}_{\mathrm{CH}_{4} \text { recovery rate, } \%}^{96.1}$ & 96.1 \\
\hline
\end{tabular}


Utility cost to produce $\mathrm{CH}_{4}$ in $\mathrm{D} 1, \$$ ton $\mathrm{CH}_{4}$

Total cost to produce $\mathrm{CH}_{4}$ in whole shale gas

separation process, $\$ /$ ton $\mathrm{CH}_{4}$

$\mathrm{C}_{2} \mathrm{H}_{6}$ purity in $\mathrm{C}_{2} \mathrm{H}_{6}$ stream, Vol\%

96.0

97.5

$\mathrm{C}_{2} \mathrm{H}_{6}$ recovery rate, $\%$

65.8

74.7

Utility cost to produce $\mathrm{C}_{2} \mathrm{H}_{6}$ in $\mathrm{D} 2$, $\$$ /ton $\mathrm{C}_{2} \mathrm{H}_{6}$

30.2

29.1

Total cost to produce $\mathrm{C}_{2} \mathrm{H}_{6}$ in whole shale gas separation process, $\$$ ton $\mathrm{C}_{2} \mathrm{H}_{6}$

Note: D1, D2 denote the two distillation columns. 


\section{Figures:}

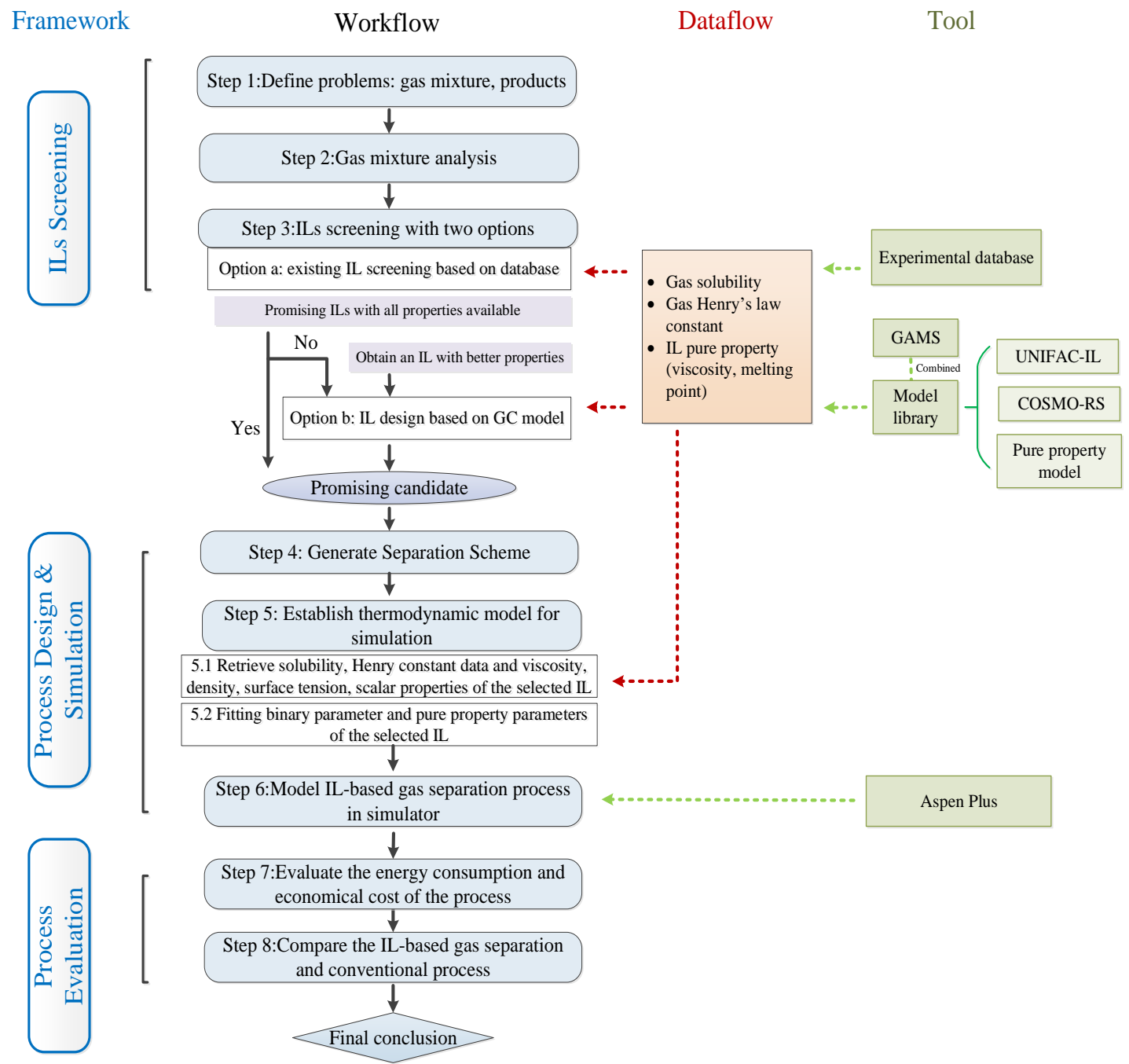

Figure 1 the whole workflow for hybrid IL-based gas separation process 


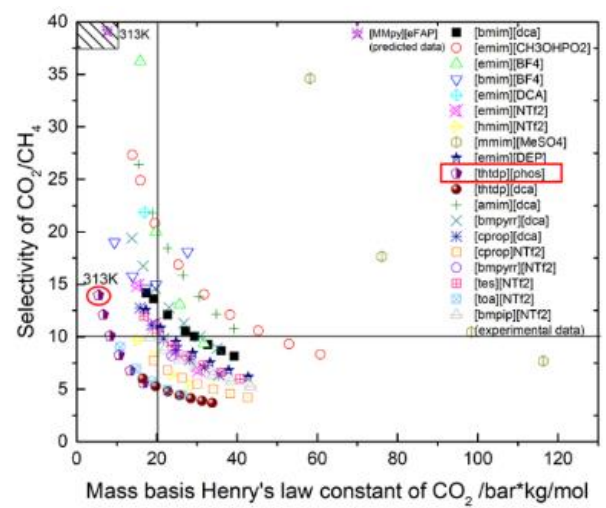

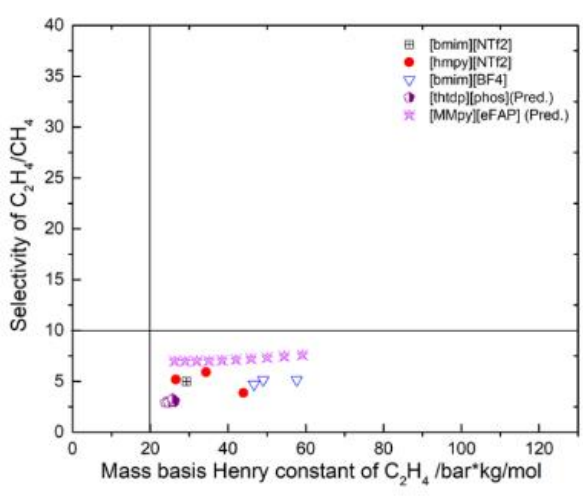

(b) (a)

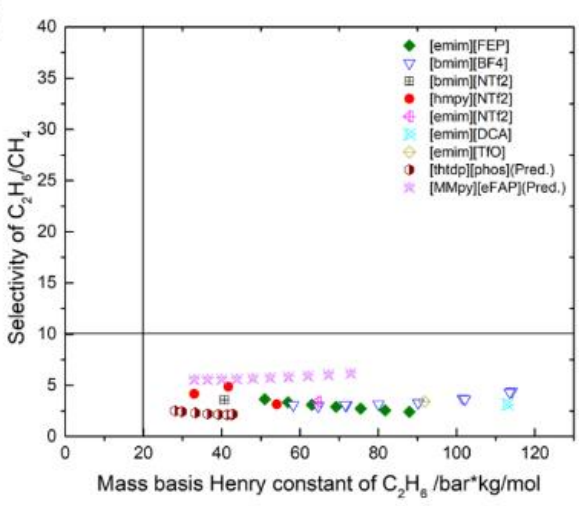

(c)

Figure 2 Henry's law constant of different gases versus selectivity to $\mathrm{CH}_{4}$ in ILs; a)

$\mathrm{CO}_{2}$, b) $\mathrm{C}_{2} \mathrm{H}_{4}$, c) $\mathrm{C}_{2} \mathrm{H}_{6}$ (Note: Pred. means predicted values)

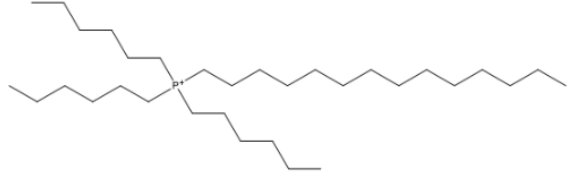

(a)<smiles>CC(CC(C)(C)C)CP(=O)([O-])CC(C)CC(C)(C)C</smiles>

(b)

Figure 3 Structure of [thtdp][phos]

$\left(\mathrm{C}_{48} \mathrm{H}_{100} \mathrm{O}_{2} \mathrm{P}_{2}\right)$; (a) cation, (b) anion

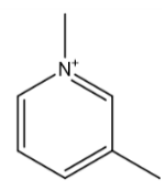

(a)

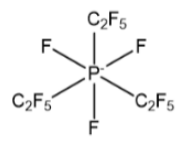

(b)

Figure 4 Structure of [MMpy][eFAP]

$\left(\mathrm{C}_{13} \mathrm{H}_{10} \mathrm{~F}_{18} \mathrm{NP}\right)$; cation (a), anion (b) 


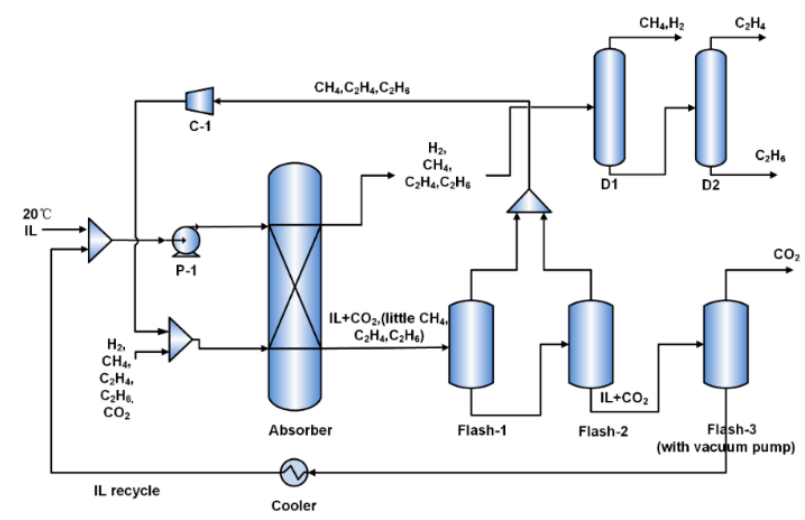

Figure 5 IL-based shale gas separation process

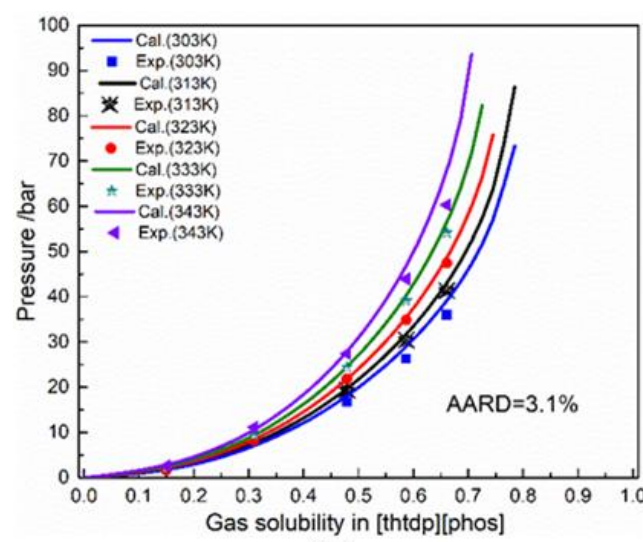

(a)

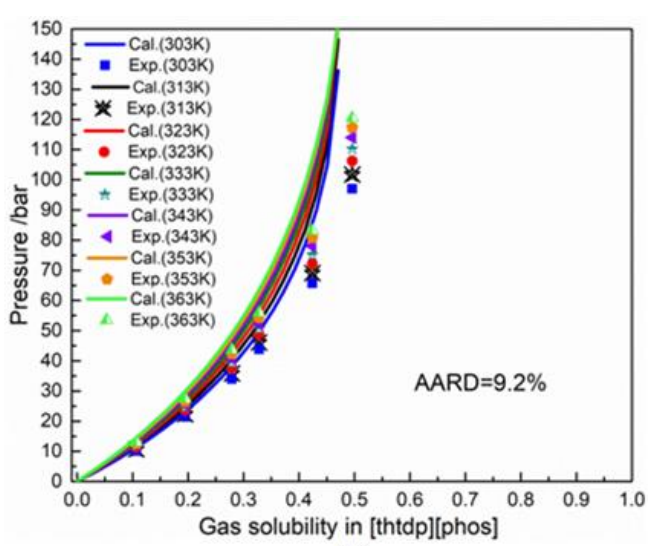

(b)

Figure 6 Simulation result of gas solubility in [thtdp][phos] from Aspen Plus: a) $\mathrm{CO}_{2}$-IL; b) $\mathrm{CH}_{4}-\mathrm{IL}$

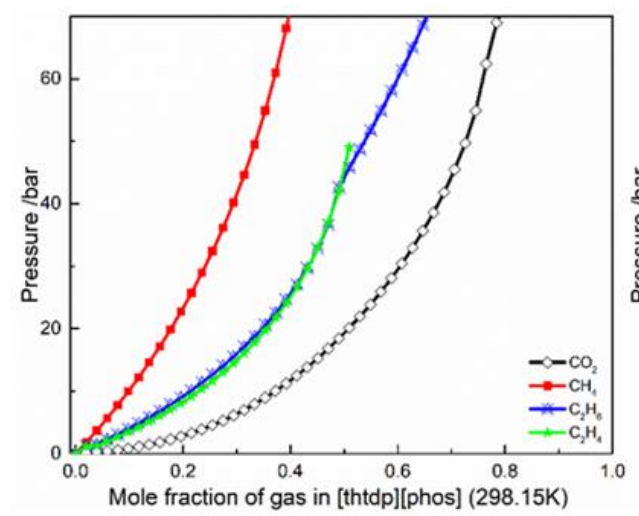

(a)

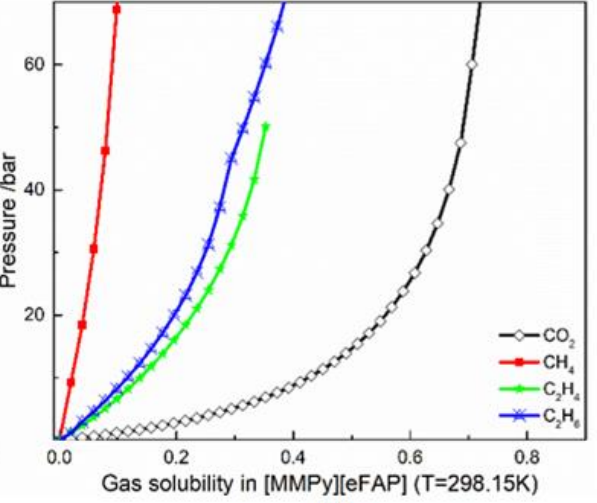

(b)

Figure 7 Simulation result of gas solubility in two ILs from Aspen Plus: a)

gas-[thtdp][phos]; b) gas -[MMPy][eFAP] 


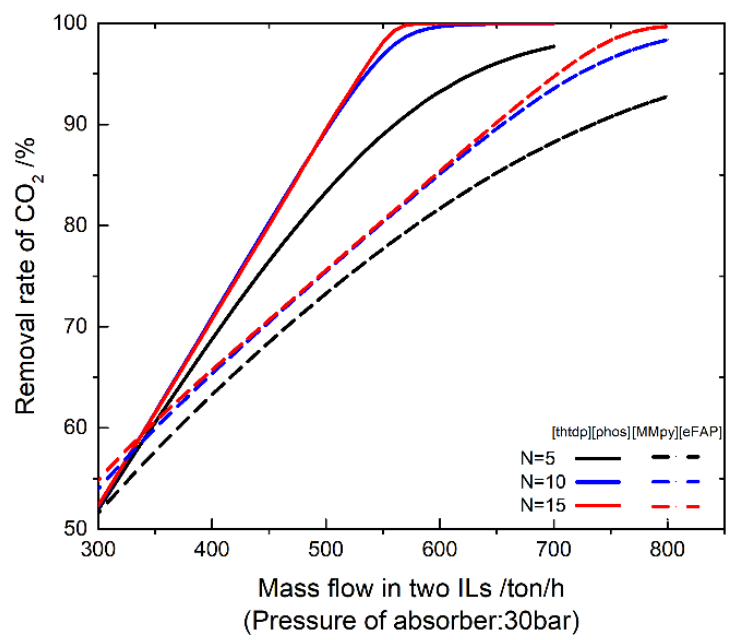

Figure $8 \mathrm{CO}_{2}$ removal rate versus IL amount in two IL-based processes. $\mathrm{N}$ means stage number.

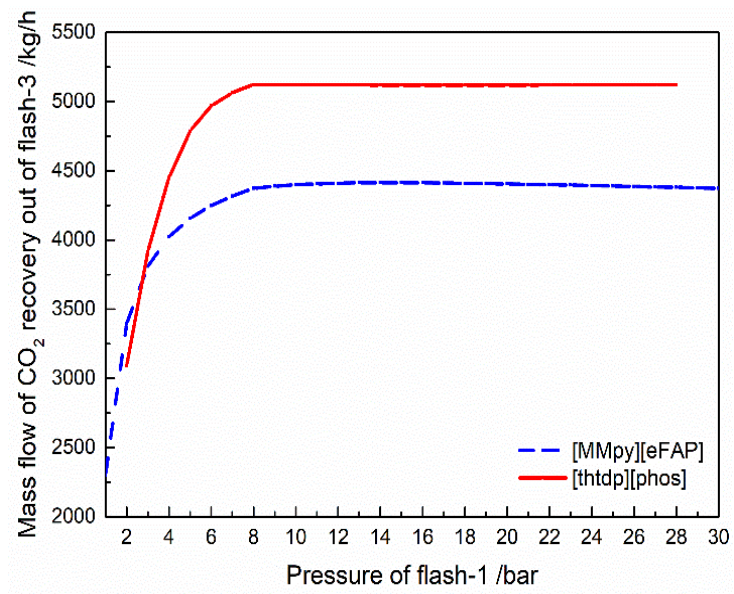

Figure 9 Pressure of flash- 1 versus mass flow of $\mathrm{CO}_{2}$ out of last flash for the two ILs considered in this work 


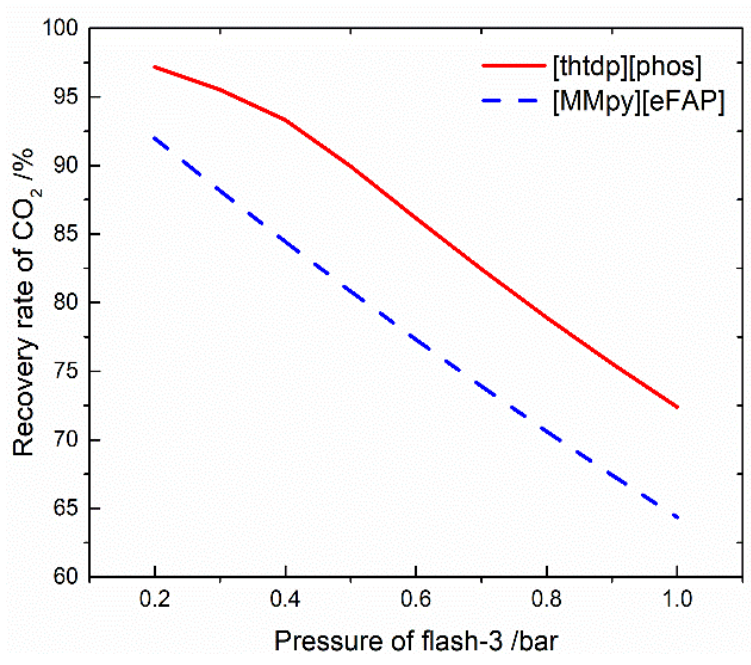

Figure 10 Temperature of flash-3 versus recovery rate of $\mathrm{CO}_{2}$ for the two ILs considered in this work

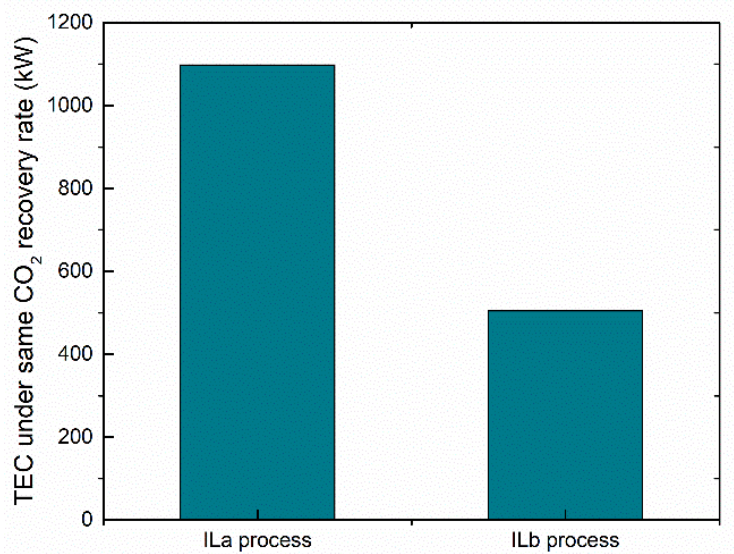

Figure 11 The total energy consumption (TEC) for the $\mathrm{CO}_{2}$ removal process in the two IL-based processes 


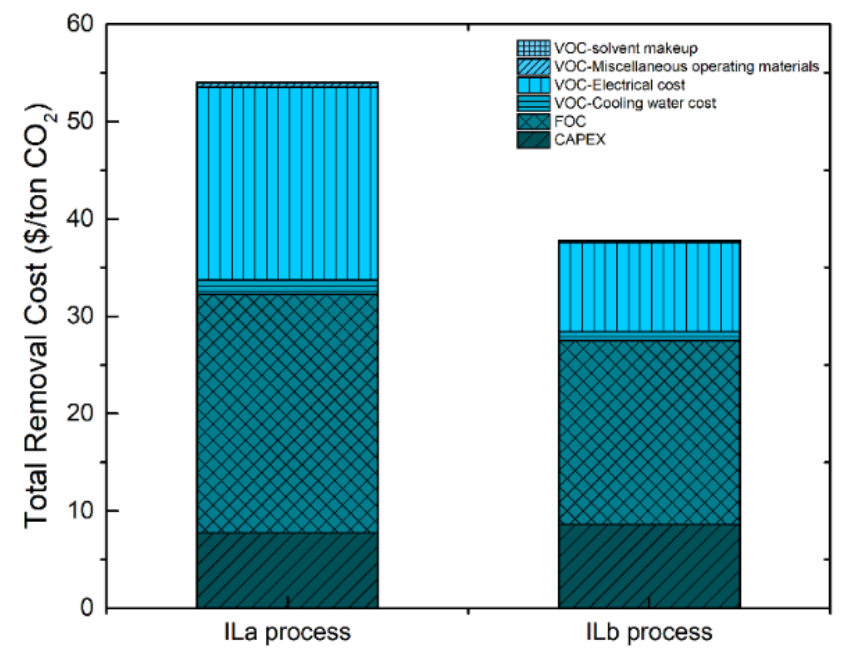

Figure 12 Comparison of total cost for $\mathrm{CO}_{2}$ removal in the two IL-based processes 